Universidade Tecnológica Federal do Paraná - UTFPR

Campus Ponta Grossa - Paraná - Brasil

ISSN: $1981-3686 /$ v. 05, n. 02: p. 584-592, 2011

D.O.I.: $10.3895 / \mathrm{S} 1981-36862011000200010$
Revista Brasileira de Tecnologia

Agroindustrial

\title{
PRODUÇÃO DE PROTEÍNA UNICELULAR A PARTIR DO RESÍDUO DA INDUSTRIALIZAÇÃO DO ABACAXI UTILIZANDO FERMENTAÇÃO EM ESTADO SEMISSÓLIDO
}

\section{PRODUCTION OF SINGLE CELL PROTEIN FROM RESIDUE OF INDUSTRIALIZATION OF PINEAPPLE USING STATE SEMI SOLID FERMENTATION}

\author{
Maria Isabel Suhet ${ }^{1}$; Romeu Fioreze ${ }^{2}$ \\ ${ }^{1}$ Instituto Federal do Espírito Santo - IFES - Alegre - Brasil isabelsuhet@ hotmail.com \\ ${ }^{2}$ Universidade Federal da Paraíba - UFPB - João Pessoa - Brasil fioreze@ terra.com.br
}

\begin{abstract}
Resumo
A produção de proteína unicelular foi avaliada na fermentação semissólida do resíduo da industrialização do abacaxi, adicionado de 0,3\% de uréia e sem adição do sal, com os fungos Rhizopus oligosporus e Aspergillus niger. O efeito da uréia no aumento de proteína e no melhor tempo de fermentação foi determinado pela análise da proteína total, pelo consumo de açúcares redutores e pela análise de $\mathrm{pH}$. A fermentação com uréia, no tempo de 72 horas, promoveu, sobre o teor protéico inicial do resíduo, aumento de $12,56 \%$ (2,72 vezes) para $R$. oligosporus e de 13,51\% (2,88 vezes) para A. niger.
\end{abstract}

Palavras-chave: resíduo agroindustrial; proteína total; fermentação semissólida; Rhizopus oligosporus; Aspergillus niger.

\section{Introdução}

O Instituto de Tecnologia de Massachusetts em 1966 criou o termo "Single Cell Protein" (SCP), para descrever a idéia de microrganismo como alimento (GIBRIEL et al., 1981) e proteína unicelular (SCP) foi admitida de forma universal para designar as células microbianas cultivadas para serem destinadas à alimentação humana e de animais. O principal processo utilizado é a fermentação em meio semissólido (FSS), bastante comum no Oriente, na produção de enzimas por meio de fungos, preparação de alimentos fermentados semelhantes a molho e miso e preservação de alimentos (CROOKE et al., 1991). A principal vantagem desse processo reside em utilizar substratos concentrados (30-60\%) de sólidos que na fermentação clássica, depende de mais energia para recuperar o produto final.

Os fungos filamentosos são considerados os melhores microrganismos para se adaptarem a essa fermentação, pela capacidade de crescimento na ausência de água livre, versatilidade de aplicação e manipulação (BALASUBRAMANIEM et al., 2001). Algumas espécies já testadas para 
produção de SCP em diferentes substratos incluem: Aspergillus niger (GIBRIEL et al., 1981), Aspergillus terreus (GARG e NEELAKANTAN, 1982; GIBRIEL et al. 1981), Aspergillus oryzae (VANNESTE, 1982), Rhizopus oligosporus (SUKARA e DOELLE, 1989), Rhizopus oryzae (DAUBRESSE et al., 1987), Trichoderma viride (VANNESTE, 1982) e Gongronella butleri (VENDRUSCOLO et al., 2007).

Diversos subprodutos agro-industriais têm sido usados como substratos para a produção de proteína unicelular, devido à disponibilidade local e por representarem uma fonte alternativa de baixo valor comercial, como cereais (GIBRIEL et al., 1981), mandioca (DAUBRESSE et al., 1987), bagaço de cana de açúcar (NIGAN, 1990) e resíduos industriais de frutas (VENDRUSCOLO et al., 2007).

Na região Nordeste, o estado da Paraíba merece destaque na produção de abacaxi, sendo que da industrialização desse fruto, 5,04\% é tido como resíduo industrial (CARVALHO e CLEMENTE, 1988). Devido à carência de pastagens na maior parte do ano, faz-se uso desse resíduo, na sua forma in natura. Normalmente resíduos de frutas são ricos em carboidratos e deficientes em proteínas. Segundo Garg e Neelakantan (1982) qualquer resíduo agrícola com menos de $8 \%$ de proteína bruta é considerado inadequado para alimento para todas as classes de animais. Para Gibriel et al. (1981) a produção de proteína por cultivo de fungo usando resíduos celulósicos como substrato, apresenta ser um caminho viável, devido à atividade celulolítica de um complexo enzimático de algumas espécies de fungos, que podem hidrolizar celulose diretamente para glucose, oferecendo um meio de cultura barato para produção de proteína.

Processos tecnológicos sofisticados para produção de proteína unicelular, não são comercialmente atrativos, especialmente em regiões mais carentes, por não serem favoravelmente econômicos. Portanto, este estudo fez considerações de alguns parâmetros na fermentação semissólida estática do resíduo de abacaxi para produção de proteína unicelular utilizando os fungos Aspergillus niger e Rhizopus oligosporus por terem sido as principais espécies isoladas nesse material por Pinto (1993). O processo teve como base a forma em que este resíduo é utilizado no estado da Paraíba para alimentação do gado, visto que, os animais têm melhor aceitação pelo material após fermentação natural.

\section{Material e métodos}

Os microrganismos utilizados foram os fungos filamentosos Rhizopus oligosporus e Aspergillus niger, cedidos pelo Laboratório de Microbiologia de Alimentos do Centro de Tecnologia (UFPB-PB), mantido em Ágar Batata Dextrose (PDA) a $4{ }^{\circ} \mathrm{C}$. Foram feitas repicagens 
em frascos Erlenmeyer com Caldo Batata Dextrose (BDA) e incubados a $30^{\circ} \mathrm{C}$ por sete dias, a fim de produzirem esporos.

\section{Meio de Cultivo}

O substrato utilizado foi o resíduo da industrialização de suco do abacaxi, da variedade pérola, composto de casca raspada para a retirada da polpa, do bagaço da polpa e do talo prensado para a extração do suco, cedidos pela Indústria Frutos Tropicais da Paraíba, apresentando composição média de 75,2 $\pm 0,16 \%$ de umidade inicial; $4,61 \pm 0,03 \%$ de proteína total, $\mathrm{pH}$ de $4,1 \pm$ 0,01 e açúcar redutor total de 29,19 \pm 0,53\%. Esse material foi triturado em pequenas partículas de 2 a $3 \mathrm{~mm}$, distribuído em recipientes em camadas de sete $\mathrm{cm}$ de espessura, inoculados com $10^{6}$ esporos/g de meio e mantidos a temperatura de 28 a $30^{\circ} \mathrm{C}$. Amostras foram retiradas nos tempos de 0, 24, 48, 72 e 96 horas de fermentação, para as análises químicas para avaliar a uréia como fonte de nitrogênio na concentração de $0,3 \%$, e o melhor tempo para produção de proteína unicelular, utilizando os fungos Rhizopus oligosporus e Aspergillus niger no meio de cultivo.

\section{Determinações Analíticas}

Neste trabalho foi determinado o conteúdo de proteína total pelo método de Kjeldahl conforme metodologia do Instituto Adolfo Lutz (1985), utilizando o fator de conversão 6,25. O consumo de açúcares redutores segundo método de Lane \& Eynon conforme descrito pelo Instituto Adolfo Lutz (1985), com uma modificação pelo uso de uma solução padrão de açúcar invertido, conforme AOAC (1995) e análise de pH conforme AOAC (1995).

O efeito do tempo de fermentação nas concentrações de proteína total, açúcar redutor total e redução do $\mathrm{pH}$ foram avaliados por regressão polinomial. Os teores de açúcar redutor total e proteína, foram submetidos à análise de correlação simples e a significância dos coeficientes, foram determinados pelo teste (t) de Student, aos níveis de cinco e 1\% de probabilidade. Para as análises, foi utilizado o programa de computação NTIA da EMBRAPA.

\section{Resultados e discussão}

\section{Açúcar redutor total}

A comparação entre teores médios de açúcares redutores totais, durante o curso das fermentações com os fungos Rhizopus oligosporus e Aspergillus niger, no substrato com e sem adição de uréia, está na Figura 1. Pode-se observar maior consumo de ART nas primeiras 24 horas para todas as fermentações, sendo que, o efeito da uréia no aumento do consumo de ART ocorreu em 24 horas na fermentação com o fungo $R$. oligosporus e em 96 horas para o fungo A. niger. 
Figura 1 - Teor de açúcar redutor total (ART) nas fermentações com $R$. oligosporus - — com uréia; $-\infty-$ sem uréia e A. Niger $\$ com uréia; $\mathbb{Z}$ sem uréia

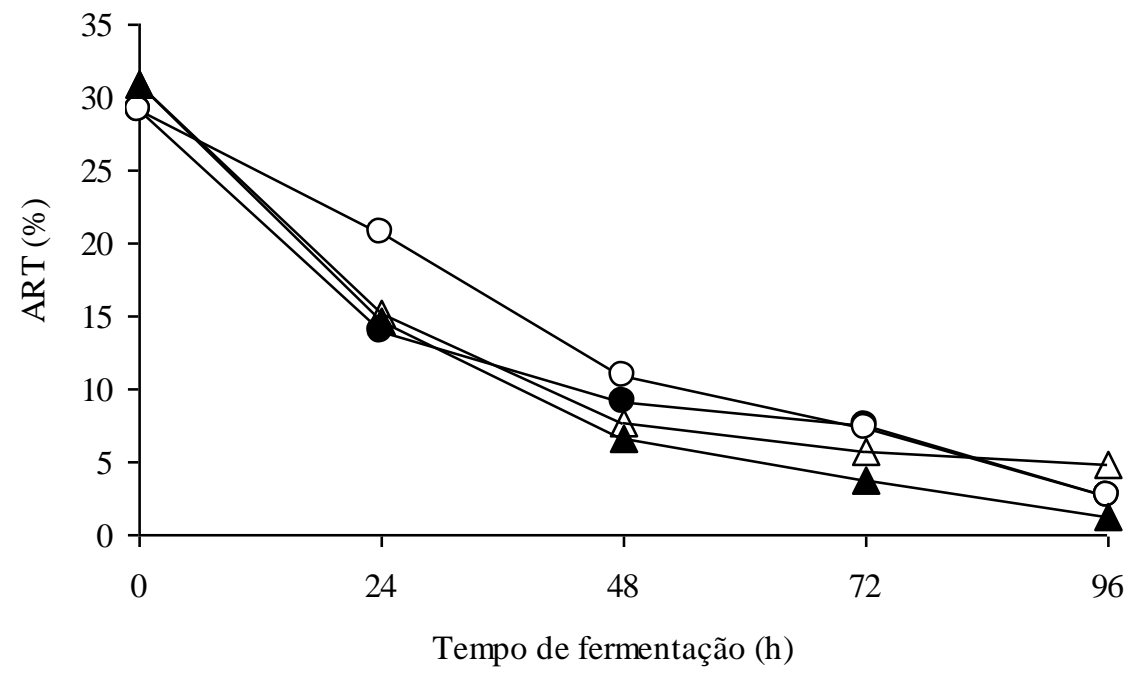

Quando feita a regressão polinomial, pode-se verificar que para a fermentação com uréia com o fungo $R$. oligosporus a concentração mínima de ART estimada foi de 3,96\% em 89 horas e com o fungo A. niger foi de 1,5\% em 84 horas de fermentação. Quando a uréia foi omitida, para a fermentação com fungo $R$. oligosporus, o teor mínimo de ART foi de $0,99 \%$ no tempo máximo de fermentação de 128 horas, enquanto para o fungo A. niger, a concentração mínima atingida foi de 4,07\% em 77 horas de fermentação.

$p H$

A Figura 2 apresenta a variação do pH no curso das fermentações.

Figura 2 - Variação do pH para as fermentações com o fungo $R$. oligosporus $\rightarrow$ com uréia; $-\infty-$ sem uréia e $A$. niger $\$$ com uréia; $\AA$ sem uréia

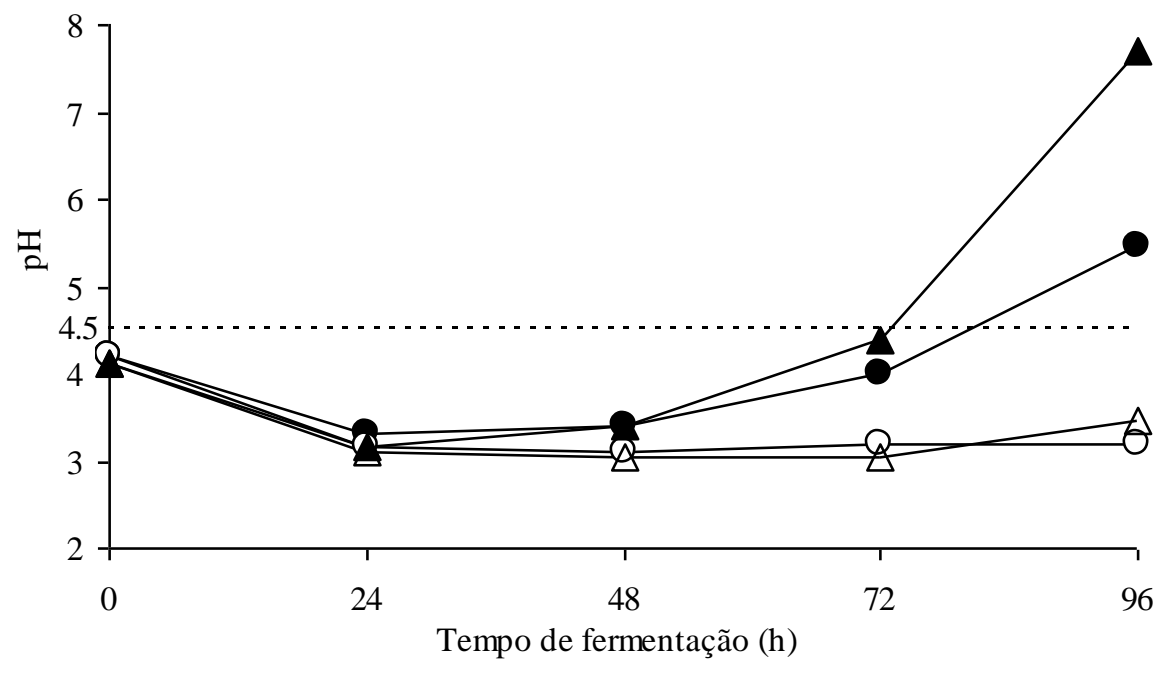


Pode-se verificar que para todas as fermentações ocorreu diminuição mais acentuada do pH nas primeiras 24 horas, atingindo o pH mínimo de 3,09. Nos substratos adicionados de uréia e fermentado com o fungo Rhizopus oligosporus, houve uma ligeira elevação do $\mathrm{pH}$ a partir das 24 horas, atingido o valor máximo de pH de 5,45 em 96 horas de fermentação. Na fermentação com o fungo Aspergillus niger, a elevação do $\mathrm{pH}$ foi mais acentuada a partir de 48 horas, atingindo o valor máximo de 7,70 em 96 horas de fermentação.

No substrato sem uréia, os valores de $\mathrm{pH}$ das fermentações mantiveram-se abaixo do $\mathrm{pH}$ do substrato inicial no tempo zero de 4,2. A redução do pH nas primeiras 24 horas de fermentação está relacionada com a taxa de consumo de açúcares, com conseqüiente produção de ácido pelos microrganismos. Os valores mínimos de $\mathrm{pH}$ obtidos nas fermentações não causaram paralisação do crescimento dos fungos, pois observou consumo dos açúcares redutores totais, exceto na fermentação com o substrato sem adição de uréia usando o fungo A. niger, em que a partir de 72 horas de fermentação o consumo de ART foi praticamente constante, atingindo a concentração mínima de 4,07\% em 77 horas de fermentação.

A elevação do $\mathrm{pH}$, a partir do ponto onde atingiu o mínimo, pode estar relacionado com a utilização simultânea dos ácidos pelos microrganismos, o que pode justificar a elevação do pH para as fermentações sem uréia. Para as fermentações com uréia, a maior elevação do $\mathrm{pH}$, pode também estar relacionada como a atividade ureásica do fungo, que liberou os íons amônia a uma velocidade superior a de assimilação pelo micélio, efeito este já descrito por Daubresse et al. (1987) que consideram o aumento do $\mathrm{pH}$ transitório porque os íons de amônia liberados são em seguida assimilados pelo fungo, e o pH tende a voltar ao valor inicial. Nesse experimento, nas fermentações com uso de uréia não se chegou a constatar, nos tempos estudados, tendência do $\mathrm{pH}$ voltar ao valor inicial. De qualquer forma, é mais interessante paralisar a fermentação em valor de $\mathrm{pH}$ menor que 4,5, e dessa forma, prevenir a germinação de esporos bacterianos. Portanto, através da observação pela Figura 2, pode-se sugerir o tempo máximo para as fermentações adicionadas de uréia de 72 horas, em pH de 3,99 para o fungo Rhizopus oligosporus e de 4,4 para o fungo Aspergillus niger.

\section{Proteína}

Na Figura 3, pode-se visualizar o comportamento para o teor protéico nas fermentações, no substrato sem e adicionado de $0,3 \%$ de uréia. Para as fermentações adicionadas de uréia, observouse um rápido aumento do teor protéico nas primeiras 24 horas de fermentação para o fungo A. niger, de 4,69 para 11,05\%, aumento de 2,36 vezes e em 48 horas para o fungo $R$. oligosporus, de 4,61 para $11,86 \%$, aumento de 2,57 vezes. Após estes tempos de fermentação, o aumento foi discreto, para ambos os fungos. 
Para a fermentação com o fungo Rhizopus oligosporus no substrato adicionado de uréia o aumento do teor protéico foi crescente atingindo o máximo de 12,53\% em 72 horas, aumento de 2,72 vezes e de 14,07\% em 96 horas de fermentação, aumento de 3,04 vezes. Quando feita a regressão polinomial, a concentração máxima foi de 14,11\%, em 106 horas de fermentação, aumento de 3,06 vezes.

Figura 3. Teor de proteína total nas fermentações com $R$. oligosporus $\rightarrow$ - com uréia; $-\infty-$ sem uréia e A. niger $\dashv$ com uréia; $\stackrel{\sim}{\sharp}$ sem uréia

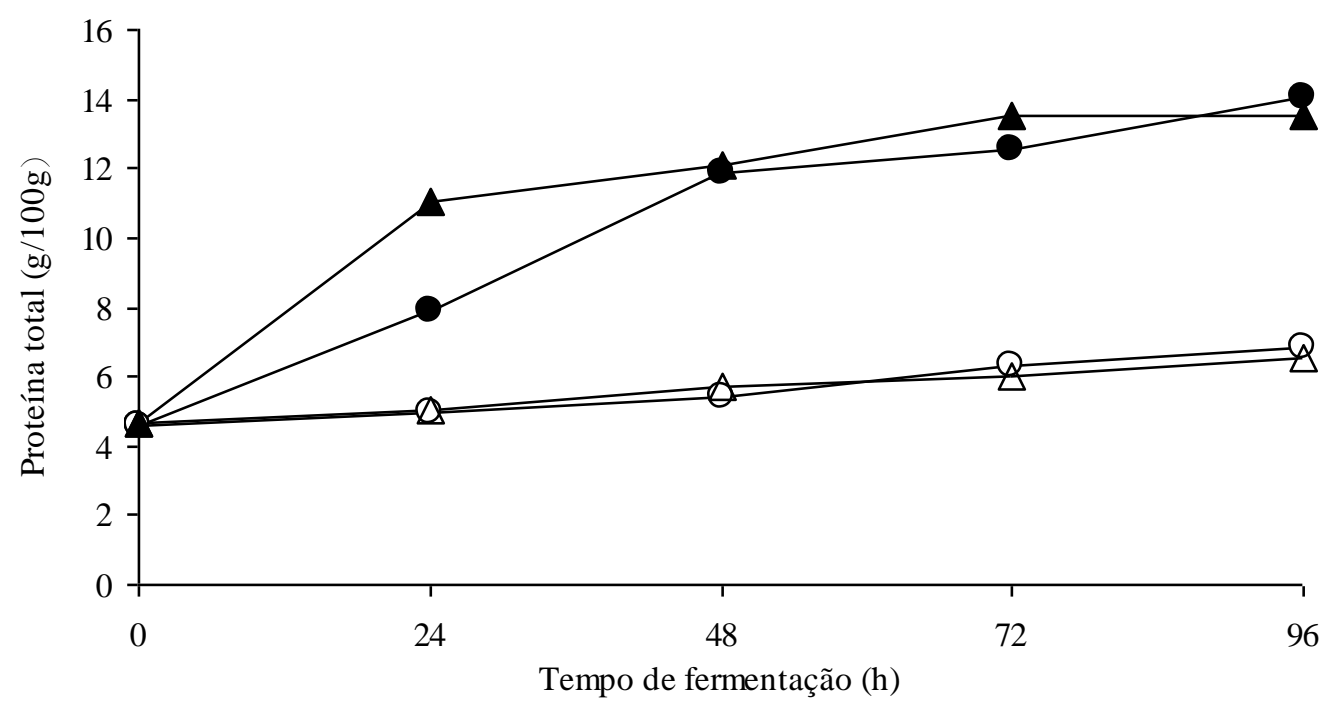

Quando a uréia foi omitida, houve um aumento linear para o conteúdo protéico, com a elevação do tempo de fermentação, através do coeficiente angular da equação obtida, esse aumento foi da ordem de aproximadamente $0,58 \%$, para cada 24 horas de fermentação, atingindo o teor em proteína de 6,83\% em 96 horas de fermentação, com um aumento de 1,48 vezes.

Para as fermentações com o fungo Aspergillus niger o aumento do teor protéico no substrato adicionado de uréia foi crescente, atingindo quantidade máxima de proteína de 13,51\% em 72 horas de fermentação, aumento de 2,88 vezes. Quando a uréia foi omitida, a quantidade de proteína aumentou linearmente com o tempo de fermentação. Pelo coeficiente angular da equação obtida, este aumento foi de aproximadamente $0,47 \%$ para cada 24 horas de fermentação, atingindo o teor máximo de proteína de 6,53\% em 96 horas de fermentação, aumento de 1,39 vezes. Sendo este incremento um pouco inferior ao estimado para a fermentação com o fungo Rhizopus oligosporus, no substrato sem uréia.

O discreto aumento verificado no teor protéico das fermentações adicionadas de uréia após 24 de fermentação para o fungo A. niger e após 48 horas para o fungo $R$. oligosporus, pode ser explicado pela deficiência de ART no meio após esse período (Figura 1); pois quando o metabolismo glicídico diminui, a esporulação é favorecida, sendo que os esporos apresentam constituição bioquímica diferente das formas vegetativas das quais são derivados. Daubresse et al. 
(1987) verificaram que depois de 65-72 horas de fermentação, houve esporulação do fungo e desenvolvimento de contaminantes, o que é preferível por não continuar a fermentação, e observou uma perda líquida de nitrogênio real total, e ao mesmo tempo, um aumento da fração não protéica (nitrogênio total), atribuindo também, o resultado obtido, a uma possível proteólise.

Houve correlação significativa e negativa do teor protéico com o açúcar redutor total ao nível de $1 \%$ de probabilidade. Verifica-se que nas fermentações com $0,3 \%$ de uréia essas correlações foram mais fortes de $(\mathrm{r}=-0,88)$ e $(\mathrm{r}=-0,98)$ que para a fermentação sem uréia $(\mathrm{r}=-0,82)$ e ( $\mathrm{r}=-0,83$ ), para os fungos Rhizopus oligosporus e Aspergillus niger, respectivamente, indicando que o consumo de ART do substrato foi inversamente proporcional a multiplicação do fungo e consequentemente ao teor protéico total. Isso indica que a quantidade de açúcar redutor total presente no substrato é um fator limitante para a multiplicação dessas espécies de fungo.

Observa-se que nas fermentações adicionadas de uréia, com o fungo Rhizopus oligosporus, o aumento do teor protéico foi de $(2,57 ; 2,72$ e 3,05) vezes para valores de $\mathrm{pH}$ de $(3,39 ; 3,99$ e 5,45) nos tempos de (48; 72 e 96) horas de fermentação, respectivamente. Para o fungo A. niger, o aumento do teor protéico foi de $(2,36 ; 2,58 ; 2,88$ e 2,88 vezes) para valores de $\mathrm{pH}$ de $(3,15 ; 3,39$; 4,4 e 7,7) em (24, 48, 72 e 96) horas de fermentação, respectivamente. Esses resultados estão próximos do encontrado por Vendruscolo et al. (2007) que obtiveram um enriquecimento protéico de 2,5 vezes sobre o teor protéico inicial do bagaço de maçã, adicionado de uréia a 5\% (p/p), unidade inicial de $70 \%$ e granulometria na faixa de 0,85 a $1,70 \mathrm{~mm}$, com o fungo Gongronella butleri CCT4274, chegando a produzir 19,24\% de proteína solúvel.

Embora, o maior aumento do teor protéico verificado no curso das fermentações tenha sido para o fungo Rhizopus oligosporus em 96 horas de fermentação e para o fungo Aspergillus niger em 72 e 96 horas de fermentação, é interessante paralisar a fermentação em pH menor que 4,5; ou seja, no tempo máximo de fermentação de 72 horas, mesmo com perda de aumento do teor protéico de 0,33 vezes na fermentação com o fungo $R$. oligosporus, mas com garantia de um produto de melhor qualidade, pela redução da contaminação bacteriana no material fermentado, conforme discutido para o $\mathrm{pH}$.

\section{Conclusão}

Nas condições que a fermentação foi conduzida, neste estudo, maiores quantidades de proteína bruta no resíduo da industrialização do abacaxi foram obtidas utilizando 0,3\% de uréia, considerando $\mathrm{pH}$ menor que 4,5, o tempo de fermentação foi de 72 horas, com produção de proteína bruta para o fungo $R$. oligosporus de $12,56 \%$, aumentando em 2,72 vezes seu conteúdo e para $A$. niger a produção de proteína bruta foi de 13,51\%, aumentando em 2,88 vezes seu conteúdo. Esse 
material fermentado ainda deve ser avaliado para a qualidade da proteína, efeito na alimentação animal e forma de conservação.

\begin{abstract}
Single cell protein production was evaluated in the fermentation semi solid of pineapple industrialization of residue, the added $0.3 \%$ urea, no salt, with the fungi Rhizopus oligosporus or Aspergillus niger. The effect of urea on increasing protein and the best time of fermentation was determinated by analysis of total protein, reducing the consumption of sugars and $\mathrm{pH}$ analysis. Fermenting the residue with urea, for 72 hours promoted the protein content of the initial residue thus increasing it to $12.56 \%$ (2.72 times) to R. oligosporus and $13.51 \%$ (2.88 times) to A. niger.

Key-words: agro-industrial residue; total protein; fermenting semi solid; Rhizopus oligosporus; Aspergillus niger.
\end{abstract}

\title{
Referências
}

AOAC. Association of Official Analytical Chemists. Official Methods of Analysis. 15. ed. Arlington: AOAC, 1995. $2 \mathrm{v}$.

BALASUBRAMANIEM, A. K.; NAGARAJAN, K. V.; PARAMASAMY, G. Optimization of media for $\beta$ fructofuranosidase production by Aspergillus niger in submerged and solid state fermentation. Process Biochemistry. v. 36, p. 1241-1247, 2001. http://dx.doi.org/10.1016/S0032-9592(01)00166-2

CARVALHO, V. D. de; CLEMENTE, P. R. Qualidade, colheita, industrialização e consumo de abacaxi. In: MEDINA, J. C.; BLEIROTH, E. W.; MARTIN, Z. J. de; SOUZA Jr., A. J.; LARA, J. C. C. de; HASHIZUME, T. Abacaxi: cultura, matéria-prima, processamento e aspectos econômicos, 2. ed. Campinas: ITAL, 1988.

CROOKE, P. S.; HONG, K.; MALANEY, G. W.; TANNER, R. D. Sólid and Semi-Sólid State Bioreactors: Static, Rotating and Fluidized Bed Fermentors. Journal Of The Biomass Energy Society of China, v. 10, n. 1/2, p. 1-17, 1991.

DAUBRESSE, P. NTIBASHIRWA, S.; GHEYSEN, A; MEYER, J. A. A process for protein enrichment of cassava by solid substrate fermentation in rural conditions. Biotechnology and Bioengineering, v. 29, p. 962-68, 1987. http://dx.doi.org/10.1002/bit.260290807

GIBRIEL, A. Y.; MAHMOUD, R. M.; GOMA, M.; ABOU-ZEID, M. Production of Single Cell Protein From Cereal by-Products. Agricultural Wastes, v. 3, p. 229-40, 1981. http://dx.doi.org/10.1016/0141-4607(81)90030-5

GARG, S. K.; NEELAKANTAN, S. Production of SCP and Cellulase by Aspergillus terreus from Bagasse Substrate. Biotechnology and Bioengineering, v. 25, p. 2407-17, 1982. http://dx.doi.org/10.1002/bit.260241108

NIGAN, P. Investigation of some factors Important for solid-stat fermentation of sugar cane bagasse for animal feed production. Enzyme and Microbial Technology, v. 12, p. 808-11, 1990. http://dx.doi.org/10.1016/01410229(90)90156-K

NORMAS ANALÍTICAS DO INSTITUTO ADOLFO LUTZ. Métodos Químicos e Físicos para Análises de Alimentos. v. 1.3 ed. São Paulo, 1985.

PINTO, H. R. de F. Secagem de Resíduos da Industrialização do Abacaxi (Ananas comosus L.). João Pessoa, 1993. 112 p. Dissertação (Mestrado em Tecnologia de Alimentos). Centro de Tecnologia - Universidade Federal da Paraíba.

SUKARA, E.; DOELLE, H. W. A one-Step Process for the Production of Single-cell Protein and Amyloglucosidase. Applied Microbiology and Biotechnology, v. 30, p. 135-40, 1989. http://dx.doi.org/10.1007/BF00264000

VANNESTE, G. Protein Enrichment of Manioc by Fungal Fermentation. Rev. Ferment. Ind. Aliment., Louvain-laNeuve, França, v. 37, n. 1, p. 19-24, 1982 (sic) 
VENDRUSCOLO, F.; KOCH, F.; PITOL, L. DE O.; NINOW, J. L. Produção de proteína unicelular a partir do bagaço de maçã utilizando fermentação em estado sólido. Revista Brasileira de Tecnologia Agroindustrial. v. 1, n. 0, p. 5357, 2007.

Submetido em 27 out. 2010; Revisão submetida pelos autores em 21 out. 2011; Aceito para publicação em 15 nov. 2011. 